\title{
AB-QTL analysis in winter wheat: II. Genetic analysis of seedling and field resistance against leaf rust in a wheat advanced backcross population
}

\author{
Ali Ahmad Naz • Antje Kunert • Volker Lind • \\ Klaus Pillen · Jens Léon
}

Received: 26 July 2007/ Accepted: 19 February 2008/Published online: 13 March 2008

(C) The Author(s) 2008

\begin{abstract}
The present study aimed to localize exotic quantitative trait locus (QTL) alleles for the improvement of leaf rust ( $P$. triticina) resistance in an advanced backcross $(\mathrm{AB})$ population, $\mathrm{B} 22$, which is derived from a cross between the winter wheat cultivar Batis (Triticum aestivum) and the synthetic wheat accession Syn022L. The latter was developed from hybridization of T. turgidum ssp. dicoccoides and T. tauschii. Altogether, $250 \mathrm{BC}_{2} \mathrm{~F}_{3}$ lines of $\mathrm{B} 22$ were assessed for seedling resistance against the leaf rust isolate $77 \mathrm{WxR}$ under controlled conditions. In addition, field resistance against leaf rust was evaluated by assessing symptom severity under natural infestation across multiple environments. Simultaneously, population B22 was genotyped with a total of 97 SSR markers, distributed over the wheat A, B and D genomes. The phenotype and
\end{abstract}

Communicated by D. Mather.

A. A. Naz · A. Kunert · V. Lind · K. Pillen · J. Léon Institute of Crop Science and Resource Conservation, Crop Genetics and Biotechnology Unit, University of Bonn, Katzenburgweg 5, 53115 Bonn, Germany

Present Address:

A. A. Naz $\cdot$ K. Pillen $(\bowtie)$

Max-Planck-Institute for Plant Breeding Research, Carl-von-Linné-Weg 10, 50829 Cologne, Germany

e-mail: pillen@mpiz-koeln.mpg.de

Present Address:

A. Kunert

Chair of Plant Breeding, Technical University of Munich,

Am Hochanger 2, 85350 Freising, Germany

Present Address:

$\mathrm{V}$. Lind

Federal Center for Breeding Research on Cultivated Plants

(BAZ), Erwin-Baur-Str. 27, 06484 Quedlinburg, Germany genotype data were subjected to QTL analysis by applying a 3-factorial mixed model analysis of variance including the marker genotype as a fixed effect and the environments, the lines and the marker by environment interactions as random effects. The QTL analysis revealed six putative QTLs for seedling resistance and seven for field resistance. For seedling resistance, the effects of exotic QTL alleles improved resistance at all detected loci. The maximum decrease of disease symptoms $(-46.3 \%)$ was associated with marker locus Xbarc149 on chromosome 1D. For field resistance, two loci had stable main effects across environments and five loci exhibited marker by environment interaction effects. The strongest effects were detected at marker locus Xbarc149 on chromosome 1D, at which the exotic allele decreased seedling symptoms by $46.3 \%$ and field symptoms by $43.6 \%$, respectively. Some of the detected QTLs co-localized with known resistance genes, while others appear to be as novel resistance loci. Our findings indicate, that the exotic wheat accession Syn022L may be useful for the improvement of leaf rust resistance in cultivated wheat.

\section{Introduction}

Wheat leaf rust, caused by the obligate parasitic fungus Puccinia triticina Eriks (syn. P. recondita Roberg ex Desmaz. f. sp. tritici), is considered to be the most widely distributed wheat disease in the world (Wiese 1987; Gupta et al. 2006). The pathogen interferes with wheat plants at all developmental stages and serious yield losses of up to $62.7 \%$ have been reported in susceptible cultivars (Singh et al. 1998). Fungicides and different cultural practices can be used to reduce yield losses. However, the development 
of resistant cultivars is the most efficient, sustainable and economic method to prevent leaf rust epidemics.

Research on leaf rust resistance in wheat has mainly concentrated on race-specific resistance that is conferred by genes with major effects and recognized by characteristic low-infection types. A battery of resistance genes (Rgenes), some of which are derived from rye and from wild relatives of wheat, is known and has been catalogued by McIntosh et al. (1995, 2003). Of these R-genes, Lr21, Lr10 and Lrl have been cloned (Huang et al. 2003a; Feuillet et al. 2003; Cloutier et al. 2007). Resistance contributed by R-genes typically remains effective for only a few years because of its dependency on the avirulence of one or a few genotypes of the relevant pathogen. Therefore, it has been suggested that the available resistance genes in hexaploid cultivated wheat have been nearly exhausted (Bai and Knott 1994). On the other hand, adult plant resistance has the potential to provide durable disease control. This form of resistance is controlled either by genes with major effects in terms of hypersensitive reaction like $L r 12$ or by slow rusting or partial resistances genes like Lr34. The parameters that cause slow rusting of a cultivar are longer latent period, low receptivity, as well as small uredial size and reduced quantity of spore production (Drijepondt and Pretorius 1989). To date, a number of adult plant resistance genes have been reported, of which Lr34 and Lr46 are the most important slow rusting genes (German and Kolmer 1992; Singh et al. 1998; Spielmeyer et al. 2005). Lr34 has been used in different breeding programs in the world because of its significance in conferring durable resistance in combinations with other genes (Dyck 1991; Singh 1992; Rosewarne et al. 2006). Currently, there is an urgent need to understand the genetic basis and quantification of such adult plant resistances as well as a quest for additional genes that could contribute to durable resistance.

Resistance genes introduced from wild species into elite cultivars have usually been genetically mapped in balanced populations of progeny derived from an early generation (e.g., $F_{2}$ plants or families or $F_{1}$-derived doubled haploids). Such populations contain an equal proportion of exotic and elite genotypes, and deleterious effects of exotic alleles may mask the desired target gene effect. The advanced backcross quantitative trait locus (AB-QTL) strategy, developed by Tanksley and Nelson (1996), has been proposed for introgression of exotic QTL alleles from a donor accession into elite germplasm. The method proved effective in detecting additive, dominant, partially dominant and overdominant QTLs. Repeated backcrossing with the elite parent decreases the number and size of the exotic introgressions, which in turn reduces the burden of linkage drag from deleterious exotic QTL alleles. Near isogenic lines can be developed readily and used for QTL verification and QTL cloning (Frary et al. 2000). AB-QTL analyses have been successfully executed to locate favorable exotic QTL alleles that could improve agronomic traits in wheat (Huang et al. 2003b, 2004; Narasimhamoorthy et al. 2006; Liu et al. 2006; Kunert et al. 2007). Leonova et al. (2007) applied the AB-QTL strategy to improve leaf rust resistance in wheat. Using $A B$ progeny derived from six exotic introgressions originating from $T$. timopheevii and T. tauschii, they detected exotic QTL alleles conferring resistance in seedlings and/or in field plots on chromosomes 2B, 2D and 6B. The strongest effect, both for seedlings and in the field was localized to a QTL on chromosome $2 \mathrm{~B}$ that explained more than $49 \%$ of the phenotypic variation.

In our study, we performed an AB-QTL analysis in order to identify QTLs associated with seedling as well as field resistance against $P$. triticina in the $\mathrm{BC}_{2} \mathrm{~F}_{3}$ population $\mathrm{B} 22$, which is derived from a cross between the elite winter wheat cultivar Batis and the exotic wheat accession Syn022L.

\section{Materials and methods}

\section{Development of the mapping population B22}

The winter wheat cultivar Batis was crossed with the synthetic wheat accession Syn022L and two backcrosses were made to Batis, using the $F_{1}$ and $B_{1} F_{1}$ plants as the maternal parents. As described by Kunert et al. (2007), the resulting $\mathrm{BC}_{2} \mathrm{~F}_{1}$ plants were self-pollinated, and single seed descent was used in order to obtain $250 \mathrm{BC}_{2} \mathrm{~F}_{3}$ plants. Progeny of each $\mathrm{BC}_{2} \mathrm{~F}_{3}$ plant were propagated in bulk until $\mathrm{BC}_{2} \mathrm{~F}_{3: 5}$ to increase the number of seeds for multi-environment testing. The recurrent parent Batis is an elite cultivar from Fr. Strube Saatzucht KG originating from the cross Bert $\times[($ Maris Huntsman $\times$ Glaucus $) \times$ Urban $]$. The primary synthetic wheat parent Syn022L was kindly provided by Professor W. Lange from the Centre for Plant Breeding and Reproduction Research (CPRO-DLO), Agriculture University Wageningen, The Netherlands. Syn022L was developed by hybridization of $T$. turgidum ssp. dicoccoides (4n, accession G168-1-2-4BM) and $T$. tauschii ( $2 n$, accession Cam L, see Lange and Jochemsen 1992a, b) and serves as the donor of wild alleles for the wheat $\mathrm{A}, \mathrm{B}$ and $\mathrm{D}$ genomes.

Evaluation of seedling resistance against $77 \mathrm{WxR}$

The $\mathrm{BC}_{2} \mathrm{~F}_{3: 5}$ lines of population $\mathrm{B} 22$ were sown in 96-cell trays in two randomized complete blocks with individual lines replicated three times within each block. Both parents were included and replicated five times per block as controls. Initially, the susceptible cultivar Borenos was 
inoculated with $P$. triticina pathotype $77 \mathrm{WxR}$ with the help of a mechanical duster. Later, the fresh spores from the preinfected seedlings of Borenos were trickled onto two-weekold seedlings of population B22. The infected plants were kept for $24 \mathrm{~h}$ in the dark at $20^{\circ} \mathrm{C}$ and $80 \%$ relative humidity to allow germination and penetration of spores, and then transferred to a growth chamber with $16 \mathrm{~h}$ light per day at $25^{\circ} \mathrm{C}$ and $80 \%$ relative humidity. After 10 days, the seedlings were screened for leaf rust symptoms using a scale from 0 to 4 . The scale values are interpreted as follows; 0 : no uredia or hypersensitive flecks without uredia, 1: small uredia surrounded by necrosis, 2: small uredia surrounded by chlorosis, 3: uredia of moderate size that might associate with chlorosis, 4: large uredia without chlorosis (modified after Long and Kolmer 1989). The virulence and avirulence pattern of the isolate is listed in Table 2. Inoculum, space and technical assistance were kindly provided by the Federal Centre for Breeding Research on Cultivated Plants (BAZ) Quedlinburg, Germany.

\section{Evaluation of field resistance}

The evaluation of field resistance was carried out under natural occurrence of leaf rust in seasons 2004 (04) and 2005 (05) at five different environments in Germany. The $\mathrm{AB}$ lines were sown in a randomized complete block design at the experimental stations Dikopshof, University of Bonn (D04 and D05), Rosenthal, Limagrain-Nickerson GmbH (R05) and Söllingen, Fr. Strube Saatzucht KG (S04 and S05). The parent Batis was included in the experiment with eight replications per environment. The synthetic parent Syn022L was not sown in the field due to lack of sufficient seed for multi-environment trials, but it had previously shown a resistant response against the natural occurrence of leaf rust in the field (data not shown). Each $\mathrm{AB}$ line and the control were sown with 310-360 kernels/ $\mathrm{m}^{2}$ and a plot size of $2.7 \mathrm{~m}^{2}$. The plots were treated with NPK fertilizer according to local practice at the respective breeding station. No fungicides were applied. Leaf rust symptom severity was scored at the maximum development of disease symptoms on a scale from 1 to 9 where 1 represents $\leq 1 \%$ and 9 represents $\geq 80 \%$ of diseased leaf area.

\section{Genetic characterization of $\mathrm{AB}$ lines}

The genetic constitution of the original $\mathrm{BC}_{2} \mathrm{~F}_{3}$ plants was analyzed with simple sequence repeat (SSR) markers. Almost 200 published SSRs from different sources (BARC, Song et al. 2005; CFA and CFD, Guyomarc'h et al. 2002; http://www.wheat.pw.usda.gov, GDM, Pestsova et al. 2000; GWM, Röder et al. 1998; WMC, Gupta et al. 2002) were tested and their chromosomal locations were assigned according to the consensus genetic map of Somers et al. (2004). Polymerase chain reaction (PCR) was used to amplify the SSR markers with the tailed primer method, where the forward primer was extended at the $5^{\prime}$-end by the M13 universal forward sequence. The PCR polymerization was performed in $20 \mu \mathrm{l}$ final volume reactions containing 5 $\mu \mathrm{l}$ of the template DNA (ca. $20 \mathrm{ng} / \mu \mathrm{l}$ ), $0.5 \mu \mathrm{l}$ of $\mathrm{Taq}$ polymerase ( 5 units/ $\mu \mathrm{l}), 0.75 \mu \mathrm{l}$ of $\mathrm{dNTP}(2 \mathrm{mM}), 0.5 \mu \mathrm{l}$ of $25 \mathrm{mM} \mathrm{MgCl}_{2}, 2 \mu \mathrm{l}$ of $10 \times$ PCR buffer $(500 \mathrm{mM} \mathrm{KCl}, 100$ $\mathrm{mM}$ Tris- $\mathrm{HCl}, \mathrm{pH} 9.0,1.0 \%$ Triton $\mathrm{X}-100), 0.2 \mu \mathrm{l}$ of each forward and reverse primer $(10 \mu \mathrm{M})$ and $0.5 \mu \mathrm{l}(1 \mu \mathrm{M})$ of the M13 universal forward primer. The latter primer was labeled at the $5^{\prime}$-end with either IRD700 or IRD800 for visualization. The amplified DNA fragments were separated electrophoretically using the Li-Cor DNA sequencer 4200, Li-Cor, Bad Homburg.

\section{QTL analysis}

Following von Korff et al. (2005), a marker analysis was executed in the general linear model (GLM) procedure of SAS version 9.1 (SAS Institute 2004) by using a 3-factorial analysis of variance (ANOVA) with a mixed hierarchical model in order to detect QTLs associated with seedling and field resistance. The two models applied are:

$y_{i j k m}=\mu+M_{i}+L_{j}\left(M_{i}\right)+B_{k}+M_{i} * B_{k}+\varepsilon_{m(i j k)}$

for seedling resistance and

$y_{i j k m}=\mu+M_{i}+L_{j}\left(M_{i}\right)+E_{k}+M_{i} * E_{k}+\varepsilon_{m(i j k)}$

for field resistance, where $\mu$ is the general mean, $M_{i}$ is the fixed effect of the $i$-th marker genotype, $L_{j}\left(M_{i}\right)$ is the random effect of the $j$-th $\mathrm{BC}_{2} \mathrm{~F}_{3}$ line nested in the $i$-th marker genotype, $E_{k}$ is the random effect of the $k$-th environment, $M_{i}{ }^{*} E_{k}$ is the random interaction effect of the $i$-th marker and $k$-th environment and $\varepsilon_{m(i j k)}$ is the error of $Y_{i j k m}$. In model [1], the random factor block $\left(B_{k}\right)$ was used instead of $E_{k}$ in order to test the reproducibility of a marker effect between blocks.

For field resistance, marker main effects $(M)$ and marker by environment interactions $\left(M^{*} E\right)$ with $P<0.01$ were accepted as putative QTLs. In contrast, for seedling resistance only marker main effects with $P<0.01$ were accepted as putative QTLs, because marker by block interactions were considered as an indication of a lack of reproducibility. Markers detecting similar effects were considered to represent a single QTL if they were within 20 cM of each other (Pillen et al. 2003).

The proportion of genetic variance $\left(R^{2} g\right)$ explained by marker main effects or marker by environment interaction effects was calculated as described by von Korff et al. (2005). The relative performance of the homozygous exotic genotype RP[exot] as a measure of trait improvement due 
to the substitution of the elite alleles (Batis) by the exotic alleles (Syn022L) was calculated according to the formula:

$\mathrm{RP}[$ exot $]=\frac{[a a]-[A A]}{A A} * 100$.

For each marker locus, [aa] and [AA] represent the least square means of disease scores of the homozygous exotic and the homozygous elite genotype, respectively, calculated across all environments and blocks, respectively.

\section{Results}

Seedling resistance

The seedling infection scores of population B22 and both parents, averaged across blocks, are displayed in Fig. 1. The donor parent Syn022L exhibited a completely resistant response in the form of a hypersensitive reaction, whereas the recurrent parent Batis displayed a highly susceptible phenotype against isolate $77 \mathrm{WxR}$. In population B22, the disease scores ranged from 0 (highly resistant) to 3.5 (highly susceptible) with a mean value of 2.5. As expected, the standard deviation was higher in population B22 than in the two controls, Batis and Syn022L.

Field resistance

Leaf rust symptoms in the field were scored in five environments (Table 1). The disease severity varied considerably across the environments and the mean disease scores of population B22 ranged from 1.7 at S04 to 4.4 at D05. An almost similar trend between the environments was observed for the recurrent parent Batis. Significantly different responses between population B22 and Batis were recorded at S04 and S05. In both cases, B22 showed higher mean disease scores than Batis. The standard deviation in

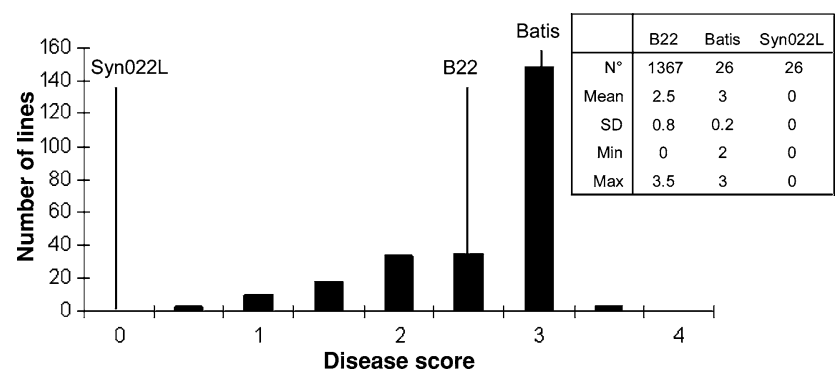

Fig. 1 Distribution of seedling disease scores against the leaf rust isolate $77 \mathrm{WxR}$ on a scale from 0 to 4 among $250 \mathrm{BC} 2 \mathrm{~F} 3$ lines of population B22. The vertical lines indicate the mean values of population B22, Batis and Syn022L. Inset: Number of observations, mean, standard deviation and minimum and maximum disease scores for population B22 and the parents Batis and Syn022L all environments was higher in population B22 than in Batis.

QTL detection

The QTLs for seedling and field resistance that were identified by applying a 3 -factorial mixed model ANOVA are summarized in Table 3 and their chromosomal location is drawn in Fig. 2.

Leaf rust seedling resistance

Six QTLs were detected for seedling resistance against the leaf rust isolate $77 \mathrm{WxR}$. At each of these, the exotic allele improved the resistance and its effect was stable across both blocks. The QTLs were located on the A genome (chromosome 6A), the $\mathrm{B}$ genome (chromosomes 1B and 4B) and the D genome (chromosomes 1D, 4D and 6D). The strongest effect of an exotic allele was detected at locus Xbarc149 on chromosome 1D where the disease score decreased by $46.3 \%$. Here, $49.0 \%$ of the genetic variation was explained by the marker main effect. At QTLs QLrs.B22-6A and QLrs.B22-4B, the exotic alleles reduced disease severity by 28.9 and $27.3 \%$, respectively. On chromosome 1B, favorable exotic alleles were detected at marker loci Xbarc8 and Xgwm11. The latter was associated with a $24.7 \%$ reduction in disease severity. Due to their close linkage, they were interpreted as a single QTL, QLrs.B22-1B. An almost 21\% reduction in disease severity was associated with an exotic allele at QLrs.B22-6D. A minor QTL effect was detected on chromosome 4D, where the exotic allele accounted for $15.0 \%$ decrease of leaf rust symptoms.

Leaf rust resistance in the field

Seven QTLs were detected for field resistance to leaf rust under natural infection across five environments. These QTLs were identified on the A, B and D genomes and appeared as marker main effects at two loci and as marker by environment $(M \times E)$ interaction effects at five loci. As for seedling resistance, the strongest QTL effect was detected at locus Xbarc149 (QLr.B22-1D). Here, the exotic allele was associated with a reduction of leaf rust symptoms by $43.6 \%$, explaining $14.6 \%$ of the genetic variation for field resistance. At this QTL, and at QLr.B22-7D, at which the exotic allele reduced symptoms by $20.9 \%$, the effect of the exotic allele was favorable in all environments but fluctuated in magnitude across the environments (Fig. 3), resulting in significant $M \times E$ interaction effects. At three QTLs, QLr.B22-1A, QLr.B22-2D and QLr.B22$6 \mathrm{D}$, the effects of the exotic alleles were favorable in some environments but unfavorable in other environments 
Table 1 Least square means (Lsmeans) and standard deviations of field resistance scores against leaf rust for population B22 and the recurrent parent Batis across five environments

\begin{tabular}{|c|c|c|c|c|c|c|c|}
\hline \multirow[t]{2}{*}{ Environment } & \multicolumn{2}{|l|}{ Batis } & \multicolumn{5}{|c|}{ Population B22 } \\
\hline & Lsmeans $^{\mathrm{a}}$ & $\mathrm{SD}^{\mathrm{b}}$ & Lsmeans $^{\mathrm{a}}$ & $\mathrm{SD}^{\mathrm{b}}$ & $\operatorname{Diff}^{c}$ & Minimum & Maximum \\
\hline D04 & $1.9^{\mathrm{C}}$ & 0.4 & $1.9^{\mathrm{C}}$ & 1.1 & $\mathrm{~ns}$ & 1 & 9 \\
\hline D05 & $4.9^{\mathrm{A}}$ & 1.4 & $4.4^{\mathrm{A}}$ & 2.2 & $\mathrm{~ns}$ & 1 & 9 \\
\hline R05 & $2.5^{\mathrm{B}}$ & 0.5 & $3.1^{\mathrm{B}}$ & 1.3 & ns & 1 & 9 \\
\hline S04 & $1.2^{\mathrm{D}}$ & 0.5 & $1.7^{\mathrm{C}}$ & 1.0 & $*$ & 1 & 8 \\
\hline S05 & $2.9^{\mathrm{B}}$ & 0.4 & $4.3^{\mathrm{A}}$ & 1.7 & $*$ & 1 & 9 \\
\hline Average & 2.4 & 0.6 & 2.9 & 1.5 & $\mathrm{~ns}$ & & \\
\hline
\end{tabular}

$n s$ not significant

* Calculated by a Tukey-Kramer test with $P<0.05$

a Significant differences between environments are indicated by different letters at $P<0.05$ after Student-Newman-Keuls (SNK) grouping implemented in the general linear model (GLM) procedure of SAS (SAS Institute 2004)

b Standard deviation

c Significant differences between Batis and B22

(Fig. 3). At two other QTLs, the exotic alleles had consistently unfavorable effects: QLr.B22-1B and QLr.B22$3 \mathrm{D}$, at which the exotic alleles increased disease severity by 27.2 and $18.1 \%$, respectively.

\section{Discussion}

An AB-QTL strategy, employing the $\mathrm{AB}$ generation $\mathrm{BC}_{2} \mathrm{~F}_{3}$, was applied in order to identify exotic QTL alleles from the synthetic wheat accession Syn022L that could contribute to resistance against leaf rust.

Assignment of QTLs for seedling and field resistance and their comparison to known resistance genes and QTLs

In population B22, QTLs for resistance against leaf rust were identified in 11 chromosome regions on wheat genomes A, B and D (see Table 3). In six of these regions, the exotic alleles consistently showed superiority over the elite genotype, indicating their potential use for wheat leaf rust resistance breeding.

The strongest effect for both leaf rust seedling and field resistance was present on chromosome 1D at marker locus Xbarc149 (QLrs.B22-1D and QLr.B22-1D). Here the exotic allele was associated with 46.3 and $43.6 \%$ reduction in leaf rust symptoms, respectively. A number of leaf rust resistance genes had already been mapped to chromosome 1D. McIntosh (1998) reported genes which are effective against leaf rust on the short arms of wheat group 1 chromosomes. In addition, Cox et al. (1994) described three leaf rust resistance genes, $L r 41, L r 42$ and $L r 43$, on chromosome 1D, which were transferred from $T$. tauschii to common wheat. The position of $\operatorname{Lr} 21$, a member of the NBS-LRR resistance gene family (Huang et al. 2003a), on chromosome arm 1DS (Jones et al. 1990) agrees with the chromosomal location of the 1D QTL in population B22. For Lr21, the USDA Cereal Disease Laboratory (http://www.ars.usda.gov/Main/docs.htm?docid=10342) recorded a low infection score $(0-2)$ at seedling stage and immunity at adult plant stage. When we inoculated the Thatcher nearly isogenic line containing $L r 21$ with our leaf rust isolate $77 \mathrm{WxR}$, the reaction was scored as virulent (see Table 2). The fact that our QTL on chromosome 1D is active both in seedling and in field experiments can be interpreted in two ways. Either a new allele of $\operatorname{Lr} 21$ which has different specificities than that present in ThatcherLr21 might be active in population B22 or a new resistance gene, independent of $L r 21$, is located on chromosome arm 1DS. In future, the genotyping of the $L r 21$ sequence in population B22 will be used to validate if this gene could explain the QTL effect in B22. Locus Xbarc149 is the only case in population B22 where the exotic allele consistently contributed to resistance both at the seedling stage and in the field experiment. Leonova et al. (2007) also reported a leaf rust resistance gene with effects at the seedling stage and in a field experiment. That gene was transferred from T. timopheevii to wheat chromosome 2B.

Some other QTLs located in population B22 potentially correspond to previously mapped resistance genes or QTLs (see Table 3). For seedling resistance, QLrs.B22-1B might correspond to $L r 26$ which was transferred from the Imperial rye (Secale cereale) chromosome $1 \mathrm{R}$ to wheat chromosome 1B (Singh et al. 1990) and QLrs.B22-6D may correspond to a QTL which was located on chromosome 6D by Nelson et al. (1997). QLrs.B22-4B is on the same chromosome as Lr31 (Singh et al. 1999) but Lr31 is 

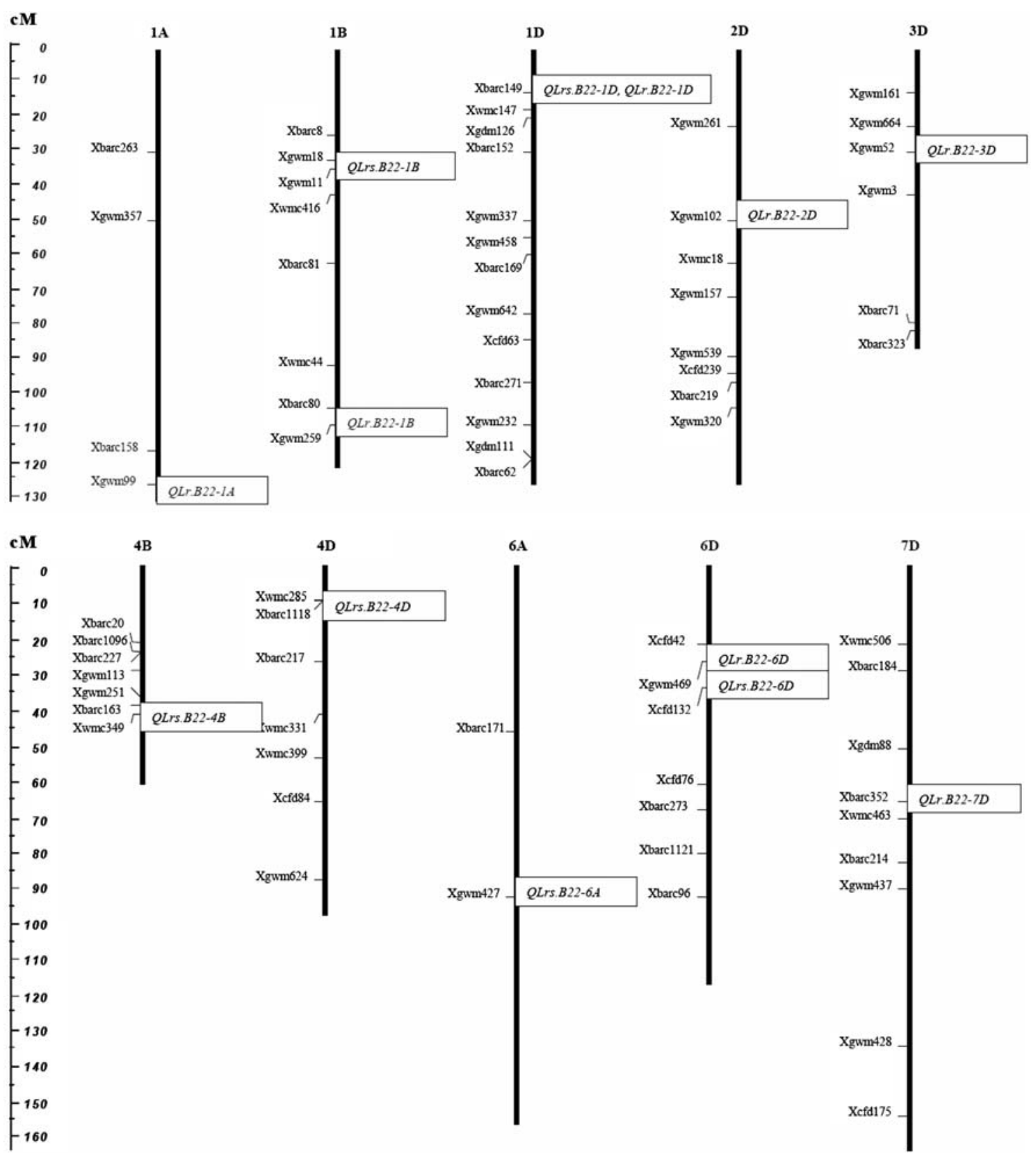

Fig. 2 Chromosomal map of population B22 showing 13 putative QTLs for leaf rust seedling and field resistance. The putative QTLs are presented at the right to the associated marker where the highest $F$-value has been calculated. The QTLs are designated according to Table 3

functional only in conjunction with $\operatorname{Lr} 27$ on chromosome 3B. The fact that no QTL in B22 has been identified on chromosome 3B might indicate that QLrs.B22-4B does not correspond to $\operatorname{Lr} 31$ and thus could be a unique resistance source. For field resistance, QTLs mapped in B22 may correspond to Lr34 on 7DS (Spielmeyer et al. 2005) and a QTL mapped on 6D by Nelson et al. (1997). Singh et al. (1993) reported that the $L r 34$ gene confers a quantitative resistance to leaf rust and Schnurbusch et al. (2004) found a similar QTL, which confers a durable slow rusting phenotype in a population derived from the cross Arina $x$
Forno. Syn022L may contribute a further resistance allele at the Lr34 locus.

In population B22, two main QTLs were mapped at which the exotic alleles on chromosomes $1 \mathrm{~B}$ and $3 \mathrm{D}$ increased leaf rust symptoms in the field. It can, thus, be concluded that the recipient parent of B22, the wheat cultivar Batis, possesses at least two resistance genes. Winzeler et al. (2000) reported that the adult plant resistance gene Lrl3 and so far unidentified resistance sources are present in Batis. However, the effect of Lr13, mapped on chromosome arm 2BS, could not be verified 
Fig. 3 Relative performance of exotic QTL alleles (RP[exot]) showing an $M \times E$ interaction effect for leaf rust symptoms in field. The RP $[$ exot $]$ value is given as a mean relative performance across all environments (hatched columns) and for five environments separately (black columns). Positive RP[exot] values indicate an increase and negative values a decrease in leaf rust severity due to the presence of the exotic allele in population B22. D04, D05, R05, S04, S05 indicate the environment as defined in "Materials and methods"

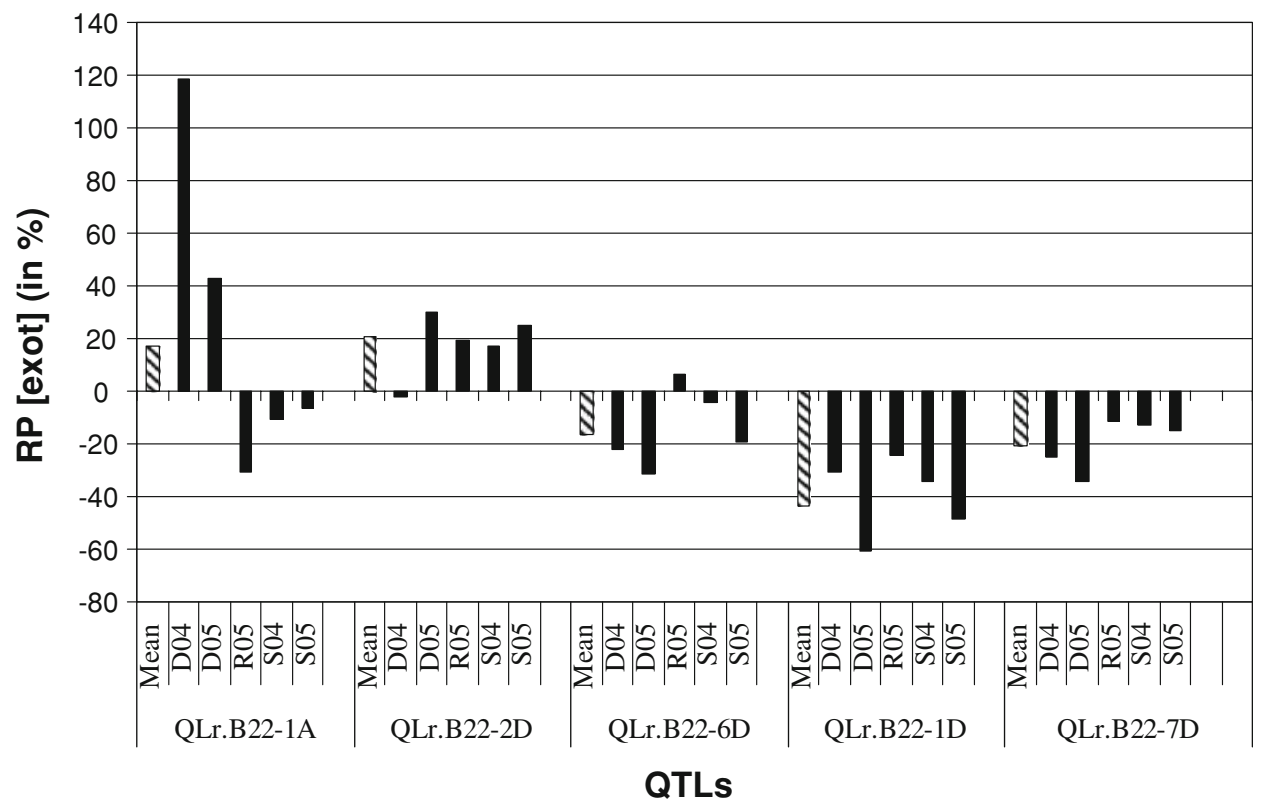

Table 2 Virulence/avirulence pattern of isolate $77 \mathrm{WxR}$ on Thatcher near-isogenic lines carrying different genes for resistance to Puccinia triticina

\begin{tabular}{|c|c|c|c|c|c|c|c|c|}
\hline Lr-gene & Infection type $\mathrm{a}^{\mathrm{a}}$ & $+/-^{\mathrm{b}}$ & Lr-gene & Infection type ${ }^{a}$ & $+1-{ }^{\mathrm{b}}$ & Lr-gene & Infection type ${ }^{\mathrm{a}}$ & $+1-{ }^{b}$ \\
\hline 1 & 3 & + & 15 & 3 & + & 30 & 2 & + \\
\hline $2 \mathrm{a}$ & 3 & + & 16 & 3 & + & 32 & 3 & + \\
\hline $2 b$ & 3 & + & $17 \mathrm{a}$ & 3 & + & 33 & 3 & + \\
\hline $2 \mathrm{c}$ & 3 & + & 18 & 3 & + & 35 & 3 & + \\
\hline 3 & 0 & - & 19 & 0 & - & 37 & 3 & + \\
\hline $3 b g$ & 0 & - & 20 & 3 & + & 38 & 0 & - \\
\hline $3 \mathrm{ka}$ & 0 & - & 21 & 2 & + & 44 & 2 & + \\
\hline 9 & 0 & - & 23 & 3 & + & 52 & 3 & + \\
\hline 10 & 2 & + & 24 & 0 & - & B & 3 & + \\
\hline 11 & 3 & + & 25 & 0 & - & Controls: & & \\
\hline 13 & 3 & + & 26 & 0 & - & Thatcher & 3 & + \\
\hline $14 \mathrm{a}$ & 2 & + & 28 & 3 & + & Batis & 3 & + \\
\hline $14 b$ & 3 & + & 29 & 0 & - & Syn022L & 0 & - \\
\hline
\end{tabular}

Data source: Dr. V. Lind, Federal Center for Breeding Research on Cultivated Plants (BAZ), Quedlinburg, Germany

a Seedling Infection was conducted and scored as explained in "Materials and methods"

b Virulence (+)/avirulence (-) pattern of isolate $77 \mathrm{WxR}$

in $\mathrm{B} 22$, either because the $P$. triticina races that differentiate $\operatorname{Lr} 13$ were not present at the environments tested or because the Batis gene at Lrl3 is matched by a similar resistance gene at this locus present in the exotic donor Syn022L.

Marker by environment interaction effects

Of the seven putative QTLs for field resistance, five (71\%) showed an $M \times E$ interaction effect in this study (see Table 3 and Fig. 3). This is in contrast to the findings of
Keller et al. (1999), who identified three of 18 QTLs showing QTL $\times$ environment interactions while studying powdery mildew resistance across five environments. An obvious reason for the higher number of $M \times E$ interactions in our study may be the fact that the selected environments were located far from each other representing different climatic conditions, altitudes and types of soil in contrary to the study of Keller et al. (1999) who investigated powdery mildew in five environments located close to each other near Zürich, at the same altitude of 450-550 $\mathrm{m}$ above the sea level on loamy soils. Moreover, they 
Table 3 Summary of QTLs for leaf rust seedling and field resistances

\begin{tabular}{|c|c|c|c|c|c|c|c|c|c|c|c|}
\hline $\mathrm{QTL}^{\mathrm{a}}$ & $\mathrm{Chr}^{\mathrm{b}}$ & Marker $^{\mathrm{c}}$ & $\begin{array}{l}\text { Range } \\
\text { (in } \mathrm{cM})^{\mathrm{d}}\end{array}$ & Effect $^{e}$ & $F$-value ${ }^{\mathrm{f}}$ & {$[\mathrm{AA}]^{\mathrm{g}}$} & $\begin{array}{l}\mathrm{RP}[\text { exot }] \\
(\text { in } \%)^{\mathrm{h}}\end{array}$ & $\begin{array}{l}\mathrm{R}^{2} \mathrm{~g} \\
(\text { in } \%)^{\mathrm{I}}\end{array}$ & $\begin{array}{l}\text { Type } \\
\text { of QTL }\end{array}$ & $\begin{array}{l}\text { Candidate } \\
\text { genes/QTLs }\end{array}$ & References \\
\hline \multicolumn{12}{|c|}{ Leaf rust seedling resistance } \\
\hline QLrs.B22-1B & $1 \mathrm{~B}$ & Xgwm11 & $24.9-34.3$ & M & 7.6 & 2.49 & -24.7 & 3.8 & I & $\operatorname{Lr} 26$ & Singh et al. (1990) \\
\hline QLrs.B22-1D & $1 \mathrm{D}$ & Xbarc149 & $13.7-16.4$ & M & 225.8 & 2.73 & -46.3 & 49.0 & I & $\operatorname{Lr} 21, \operatorname{Lr} 42$ & $\begin{array}{l}\text { Spielmeyer et al. (2000), } \\
\text { Cox et al. (1994). }\end{array}$ \\
\hline QLrs.B22-4B & $4 \mathrm{~B}$ & Xwmc349 & 40.6 & M & 15.8 & 2.52 & -27.3 & 6.6 & I & & \\
\hline QLrs.B22-4D & $4 \mathrm{D}$ & Xbarc1118 & 10 & M & 7.1 & 2.52 & -15.0 & 3.4 & I & & \\
\hline QLrs.B22-6A & $6 \mathrm{~A}$ & Xgwm427 & 93.2 & M & 8.1 & 2.50 & -28.9 & 3.7 & I & & \\
\hline QLrs.B22-6D & $6 \mathrm{D}$ & Xcfd132 & 34.6 & M & 7.8 & 2.51 & -20.6 & 3.2 & I & QTL & Nelson et al. (1997). \\
\hline \multicolumn{12}{|c|}{ Leaf rust field resistance } \\
\hline QLr.B22-1A & $1 \mathrm{~A}$ & Xgwm99 & 126 & $M \times E$ & 7.2 & 3.06 & co & 3.3 & III & & \\
\hline QLr.B22-1B & 1B & Xgwm259 & $91.5-106.8$ & $M$ & 9.8 & 2.95 & 27.2 & 6.3 & I & & \\
\hline QLr.B22-1D & $1 \mathrm{D}$ & Xbarc149 & $13.7-18.8$ & $M \times E$ & 34.7 & 3.34 & -43.6 & 14.6 & II & $\operatorname{Lr} 21$ & $\begin{array}{l}\text { Spielmeyer et al. (2000), } \\
\text { Huang et al. (2003a) }\end{array}$ \\
\hline QLr.B22-2D & $2 \mathrm{D}$ & Xgwm102 & 48.2 & $M \times E$ & 7.1 & 3.0 & co & 3.1 & III & QTL & Leonova et al. (2007). \\
\hline QLr.B22-3D & $3 \mathrm{D}$ & Xgwm52 & 29.8 & $M$ & 8.6 & 2.96 & 18.1 & 3.4 & I & & \\
\hline QLr.B22-6D & $6 \mathrm{D}$ & Xgwm469 & 25 & $M \times E$ & 4.3 & 3.09 & co & 2.0 & III & QTL & Nelson et al. (1997). \\
\hline QLr.B22-7D & $7 \mathrm{D}$ & Xbarc352 & 66 & $\mathrm{M} \times \mathrm{E}$ & 4.0 & 3.16 & -20.9 & 1.9 & II & Lr34, QTL & $\begin{array}{l}\text { Singh et al. (1993), } \\
\text { Schnurbusch et al. (2004), } \\
\text { Spielmeyer et al. (2005). }\end{array}$ \\
\hline
\end{tabular}

${ }^{a}$ Quantitative trait locus, names comprise the identifier Q, the trait and the population investigated and the chromosomal location of the QTL

${ }^{\mathrm{b}}$ Chr: Chromosome

c SSR marker showing the highest $F$-value in the ANOVA

${ }^{\mathrm{d}}$ CentiMorgan position from the first to the last significant marker in a QTL region

${ }^{\mathrm{e}}$ Indication whether a marker main effect $(M)$ or a marker by environment interaction $(M \times E)$ is significant with $P<0.01$

${ }^{\text {f }} F$-value of the given $M$ or $M \times E$ effect

$\mathrm{g}$ Leaf rust least squares means of the homozygous elite genotypes [AA] at the given marker locus

h Relative performance of the homozygous exotic genotype. For calculation see "Materials and methods"

${ }^{\text {i }}$ Genetic variance explained by $M$ or $M \times E$. For calculation see von Korff et al. (2005)

j Type of QTL effect which is either a marker main effect (I), a stable marker by environment interaction effect, always showing a favorable respectively unfavorable exotic effect across the environments (II), or a cross over (co) marker by environment interaction, showing contrasting exotic effects between the environments (III)

${ }^{\mathrm{k}}$ Possible candidate genes or corresponding QTLs, based on co-localization with B22 QTLs

reported a medium disease pressure in their studies in both natural and artificial inoculations and they used growth regulators to further decrease the sampling and testing errors. In this study, the field experiments were grown under natural infestation and without the use of growth regulators. $M \times E$ interactions could be higher in our study because of the diversity of pathogens present in the environments investigated. Furthermore, disease symptoms depend primarily on the environmental condition, i.e., temperature, humidity, light, etc., which presumably were not constant across all environments tested. However, the differentiation of QTLs into stable and environmentdependent QTLs has important implications for markerassisted selection. In future, the stable QTLs could be used for marker-assisted selection across all environments while the environment-dependent QTLs may be restricted to specific environments.

\section{Outlook}

The present study was designed to identify exotic QTL alleles which affect leaf rust seedling and field resistance in the $\mathrm{BC}_{2} \mathrm{~F}_{3}$ population B22. Altogether, QTLs were detected in 11 chromosome regions. At most loci, the exotic alleles improved resistance. QTLs, at marker Xbarc149 on chromosome 1D, QLrs.B22-1D and QLr.B22-1D, explained high proportions of the genetic variance for seedling resistance $(49.0 \%)$ and field resistance (14.6\%). In future, $\mathrm{BC}_{2} \mathrm{~F}_{3}$ lines of population $\mathrm{B} 22$ which possess exotic resistance QTL alleles can be utilized to generate QTL- 
bearing nearly-isogenic lines (NILs) via backcrossing with Batis and marker-assisted selection. These NILs can be used to verify the QTL effects in new field experiments. If verified, the NILs can be directly used both for development of improved varieties and for map-based cloning of the QTL-underlying resistance genes.

Acknowledgments We express our thanks to the plant breeders Dr. E. Ebmeyer (Lochow-Petkus), Dr. J. Schacht (Limagrain Nickerson), Dr. A. Spanakakis (Fr. Strube Saatzucht), Dr. E. Kazman (Saatzucht Josef Breun) and their breeding station teams for the evaluation of leaf rust occurrence. We also appreciate the contribution of Mr. W. Bungert and Mr. H. Rehkopf for supporting field trials at the Research Station Dikopshof, University of Bonn, and of Ms. Remus, BAZ Quedlinburg, for leaf rust inoculations at the seedling stage. Finally, we are grateful to P. Kerwer, O. Dedeck, S. Gehlen and C. Golletz for assistance in SSR genotyping. The project was funded by the German Plant Genome Research Initiative (GABI, Project 312862), Federal Ministry of Education and Research (BMBF).

Open Access This article is distributed under the terms of the Creative Commons Attribution Noncommercial License which permits any noncommercial use, distribution, and reproduction in any medium, provided the original author(s) and source are credited.

\section{References}

Bai DP, Knott DR (1994) Genetic studies of leaf and stem rust resistance in six accessions of Triticum turgidum var dicoccoides. Genome 37:405-409

Cox TS, Raupp WJ, Gill BS (1994) Leaf rust-resistance genes Lr41, Lr42 and Lr43 transferred from Triticum tauschii to common wheat. Crop Sci 34:339-343

Cloutier S, McCallum BD, Loutre C, Banks TW, Wicker T, Feuillet C, Keller B, Jordan MC (2007) Leaf rust resistance gene Lrl, isolated from bread wheat (Triticum aestivum L.) is a member of the large psr567 gene family. Plant Mol Biol 65:93-106

Drijepondt SC, Pretorius ZA (1989) Greenhouse evaluation of adultplant resistance conferred by the gene $\operatorname{Lr} 34$ to leaf rust of wheat. Plant Dis 73:669-671

Dyck PL (1991) Genetics of adult plant resistance in Chinese spring and sturdy wheats. Crop Sci 31:309-311

Frary A, Nesbitt TC, Frary A, Grandillo S, van der Knaap E, Cong B, Liu J, Meller J, Elber R, Alpert KB, Tanksley SD (2000) fw2.2: a quantitative trait locus key to the evolution of tomato fruit size. Science 289:85-88

Feuillet C, Travella S, Stein N, Albar L, Nublat A, Keller B (2003) Map-based isolation of the leaf rust disease resistance gene $\mathrm{LrlO}$ from the hexaploid wheat (Triticum aestivum L.) genome. Proc Natl Acad Sci USA 100:15253-15258

German SE, Kolmer JA (1992) Effect of gene Lr34 on the enhancement of resistance to leaf rust of wheat. Theor Appl Genet 84:97-105

Gupta PK, Balyan HS, Edwards KJ, Isaac P, Korzun V, Röder MS (2002) Genetic mapping of 66 new microsatellite (SSR) loci in bread wheat. Theor Appl Genet 105:413-422

Gupta SK, Charpe A, Prabhu KV, Haque QMR (2006) Identification and validation of molecular markers linked to the leaf rust resistance gene Lr19 in wheat. Theor Appl Genet 113:10271036

Guyomarc'h H, Sourdille P, Charmet G, Edwards KJ, Bernard M (2002) Characterisation of polymorphic microsatellite markers from Aegilops tauschii and transferability to the D-genome of bread wheat. Theor Appl Genet 104:1164-1172

Huang L, Brooks SA, Li WL, Fellers JP, Trick HN, Gill BS (2003a) Map-based cloning of leaf rust resistance gene $L r 21$ from the large and polyploid genome of bread wheat. Genetics 164:655-664

Huang XQ, Cöster H, Ganal MW, Röder MS (2003b) Advanced backcross QTL analysis for the identification of quantitative trait loci alleles from wild relatives of wheat (Triticum aestivum L.). Theor Appl Genet 106:1379-1389

Huang XQ, Kempf H, Ganal MW, Röder MS (2004) Advanced backcross QTL analysis in progenies derived from a cross between a German elite winter wheat variety and a synthetic wheat (Triticum aestivum L.). Theor Appl Genet 109:933-943

Jones SS, Dvorak J, Qualset CO (1990) Linkage relations of Gli-D1, $R g 2$, and $L r 21$ on the short arm of chromosome-1D in wheat. Genome 33:937-940

Keller M, Keller B, Schachermayr G, Winzeler M, Schmid JE, Stamp P, Messmer MM (1999) Quantitative trait loci for resistance against powdery mildew in a segregating wheat $\times$ spelt population. Theor Appl Genet 98:903-912

Kunert A, Naz A, Dedeck O, Pillen K, Léon J (2007) AB-QTL analysis in winter wheat: I. Detection of favorable exotic alleles for baking quality traits introgressed from synthetic hexaploid wheat (T. turgidum ssp. Dicoccoides $\times T$. tauschii). Theor Appl Genet (in press)

Lange W, Jochemsen G (1992a) Use of gene pool of Triticum turgidum ssp. dicoccoides and Aegilops squarrosa for the breeding of common wheat ( $T$. aestivum) through chromosomal double hybrids. I. Two strategies for the production of amphiploids. Euphytica 59:197-212

Lange W, Jochemsen G (1992b) Use of gene pool of Triticum turgidum ssp. dicoccoides and Aegilops squarrosa for the breeding of common wheat (T. aestivum). through chromosomal double hybrids. II. Morphology and meiosis of the amphiploids. Euphytica 59:213-220

Leonova IN, Laikova LI, Popova OM, Unger O, Börner A, Röder MS (2007) Detection of quantitative trait loci for leaf rust resistance in wheat-T. timopheevii/T. tauschii introgression lines. Euphytica 155:79-86

Liu S, Zhou R, Dong Y, Li P, Jia J (2006) Development, utilization of introgression lines using a synthetic wheat as donor. Theor Appl Genet 112:1360-1373

Long DL, Kolmer JA (1989) A North-American system of nomenclature for Puccinia recondita f.sp. tritici. Phytopathology 79:525-529

McIntosh RA (1998) Breeding wheat for resistance to biotic stresses. In: Braun HJ et al (eds) Wheat prospects for global improvement. Kluwer Academic Press, Dordrecht, pp 71-81

McIntosh RA, Hart GE, Gale MD (1995) Catalogue of gene symbols for wheat. In: Li ZS, Xin ZY (eds) Proceedings of the 8th international wheat genetics symposium, Beijing, 20-25th July 1993. China Agriculture Sciencetech, Beijing, pp 1333-1500

McIntosh RA, Yamazaki Y, Devos KM, Dubkovsky J, Rogers WJ, Appels R (2003) Catalogue of gene symbols. In: KOMUGIintegrated wheat science database. http://www.grs.nig.ac.jp./ wheat/komugi/genes

Narasimhamoorthy B, Gill BS, Fritz AK, Nelson JC, Brown-Guedira GL (2006) Advanced backcross QTL analysis of a hard winter wheat $\times$ synthetic wheat population. Theor Appl Genet 112:787-796

Nelson JC, Singh RP, Autrique JE, Sorrells ME (1997) Mapping genes conferring and suppressing leaf rust resistance in wheat. Crop Sci 37:1928-1935

Pestsova E, Ganal MW, Röder MS (2000) Isolation and mapping of microsatellite markers specific for the $\mathrm{D}$ genome of bread wheat. Genome 43:689-697 
Pillen K, Zacharias A, Léon J (2003) Advanced backcross QTL analysis in barley (Hordeum vulgare L.). Theor Appl Genet 107:340-352

Röder MS, Korzun V, Wendehake K, Plaschke J, Tixier M-H, Leroy P, Ganal MW (1998) A microsatellite map of wheat. Genetics 149:2007-2023

Rosewarne GM, Singh RP, Huerta-Espino J, Willian HM, Bouchet S, Cloutier S, McFadden H, Lagudah ES (2006) Leaf tip necrosis, molecular markers and $\beta 1$-proteasome subunits associated with slow rusting resistance gene Lr46/Yr29. Theor Appl Genet 112:500-508

SAS Institute (2004) The SAS system for Windows, release 9.1. SAS Institute, Cary

Schnurbusch T, Bossolini E, Messmer M, Keller B (2004) Tagging and validation of a major quantitative trait locus for leaf rust resistance and leaf tip necrosis in winter wheat cultivar Forno. Phytopathology 94:1036-1041

Singh NK, Shepherd KW, McIntosh RA (1990) Linkage mapping of genes for resistance to leaf, stem and stripe rusts and $\omega$-secalins on short arm of rye chromosome 1R. Theor Appl Genet 80:609-616

Singh RP (1992) Association between gene Lr34 for leaf rust resistance and leaf tip necrosis in wheat. Crop Sci 32:874-878

Singh RP, Bechere E, Abdalla O (1993) Genetic-analysis of resistance to leaf rust in 9 nine Durum wheats. Plant Dis 77:460-463

Singh RP, Mujeeb-Kazi A, Huerta-Espino J (1998) Lr46: A gene conferring slow-rusting resistance to leaf rust in wheat. Phytopathology 88:890-894

Singh D, Park RF, McIntosh RA (1999) Genetic relationship between the adult plant resistance gene $\operatorname{Lr} 12$ and the complementary gene Lr31 for seedling resistance to leaf rust in common wheat. Plant Pathol 48:567-573
Somers JD, Isaac P, Edwards K (2004) A high-density microsatellite consensus map for bread-wheat (Triticum aestivum L.). Theor Appl Genet 109:1105-1114

Song QJ, Shi JR, Singh S, Fickus EW, Costa JM, Lewis J, Gill BS, Ward R, Cregan PB (2005) Development and mapping of microsatellite (SSR) markers in wheat. Theor Appl Genet 110:550-560

Spielmeyer W, Huang L, Bariana H, Laroche A, Gill BS, Lagudah ES (2000) NBS-LRR sequence family is associated with leaf and stripe rust resistance on the end of homoeologous chromosome group 1S of wheat. Theor Appl Genet 101:1139-1144

Spielmeyer W, McIntosh RA, Kolmer J, Lagudah ES (2005) Powdery mildew resistance and Lr34/Yr18 genes for durable resistance to leaf and stripe rust cosegregate at a locus on the short arm of chromosome 7D of wheat. Theor Appl Genet 111:731-735

Tanksley SD, Nelson JC (1996) Advanced backcross QTL analysis: a method for simultaneous discovery and transfer of valuable QTL from unadapted germplasm into elite breeding lines. Theor Appl Genet 92:191-203

von Korff M, Wang H, Léon J, Pillen K (2005) AB-QTL analysis in spring barley. I. Detection of resistance genes against powdery mildew, leaf rust and scald introgressed from wild barley. Theor Appl Genet 111:583-590

Wiese MV (1987) Compendium of wheat diseases, 2nd edn. Amercian Phytopathological Society Press, St Paul

Winzeler M, Mesterhazy A, Park RF, Bartos P, Csosz M, Goyeau H, Ittu M, Jones $\mathrm{E}$, Löschenberger $\mathrm{F}$, Manninger $\mathrm{K}$, Pasquini $\mathrm{M}$, Richter K, Rubiales D, Schachermayer G, Strzembicka A, Trottet M, Unger O, Vida G, Walther U (2000) Resistance of European winter wheat germplasm to leaf rust. Agronomie 20:783-792 